\title{
Pteridoflora do Engenho Água Azul, município de Timbaúba, Pernambuco, BrasiL ${ }^{1}$
}

\author{
Marcio Roberto Pietrobom ${ }^{2}$ \& Iva Carneiro Leão Barros ${ }^{3}$
}

\section{Resumo}

(Pteridoflora do Engenho Água Azul, município de Timbaúba, Pernambuco, Brasil) O presente trabalho apresenta a análise florística das pteridófitas ocorrentes no fragmento florestal Engenho Água Azul, município de Timbaúba, estado de Pernambuco, Brasil. A área abrange cerca de 600 ha de vegetação que se enquadra no tipo Floresta Ombrófila Densa Submontana, com altitudes entre 304-451m, e coordenadas geográficas $35^{\circ} 22^{\prime} 42,9^{\prime \prime} \mathrm{W}-07^{\circ} 36^{\prime} 31,5^{\prime \prime} \mathrm{S}$. Os resultados indicaram a ocorrência de 16 famílias, 42 gêneros e 85 espécies. As famílias mais representadas na área em número de espécies foram Pteridaceae com 18, Polypodiaceae e Dryopteridaceae, ambas com 10, e Thelypteridaceae com oito. Em número de gêneros foram Dryopteridaceae e Polypodiaceae ambas com sete e Pteridaceae com seis. Os gêneros com maior número de espécies são Adiantum (12 spp.) e Thelypteris (7 spp.). A pteridoflora estudada está representada por 53 espécies com distribuição geográfica restrita às Américas, nove espécies Pantropicais, 13 espécies restrita a América do Sul e oito espécies restritas ao Brasil. A maioria das espécies se apresentou como terrícolas e hemicriptófitas rosuladas, ocorrendo no interior da mata em barrancos ao longo de cursos d'água e afloramentos rochosos. Palavras-chave: Pteridófitas, Florística, Ecologia, Floresta Atlântica, Nordeste.

\section{Abstract}

(Pteridophytes of Engenho Água Azul, municipality of Timbaúba, Pernambuco, Brazil) This study presents a floristic survey of the pteridophytes occurring in the forest fragment of Engenho Água Azul, municipality of Timbaúba, State of Pernambuco, Brazil. The area has about 600 ha Atlantic forest with 304-451m altitude, and geographical coordinates $35^{\circ} 22^{\prime} 42,9^{\prime \prime} \mathrm{W}-07^{\circ} 36^{\prime} 31,5^{\prime \prime} \mathrm{S}$. The study indicated the occurrence of 16 families, 42 genera, and 85 species. The most representative families in number of species were Pteridaceae with 18 , Polypodiaceae and Dryopteridaceae both with 10 and Thelypteridaceae with eight, and in number of genera were Dryopteridaceae and Polypodiaceae both with seven and Pteridaceae with six. The genera with the highest number of species were Adiantum (12 spp.) and Thelypteris (7 spp.). The Pteridophytic flora is represented by 53 species with geographical distribution restricted to America, nine species Pantropical, 13 species for the South America and eight species restricted to Brazil. Most species are terrestrial and hemicriptophitic, occurring in the interior of the forest fragment in cliffs along courses of creeks and rocky. Key words: Pteridophytes, Floristic, Ecology, Atlantic Forest, Northeast.

\section{INTRODUÇÃO}

A considerável diversidade de formas biológicas observadas nas pteridófitas demonstra a capacidade dessas plantas em habitar diversos micro-ambientes. As florestas úmidas propiciam, condições favoráveis a diversidade e abundância desse grupo de plantas (Senna \& Waechter 1997).

Segundo Barros et al. (2002), a maioria dos gêneros e espécies de pteridófitas ocorrentes em Pernambuco são encontrados em formações florestais, principalmente na floresta atlântica (Zona da Mata) e nas florestas serranas (Agreste e Sertão).

Considerando a zona da mata norte do estado (segundo a classificação de AndradeLima 1960), ainda são poucos os trabalhos publicados que tratam sobre a composição florística das pteridófitas, destacando-se os de Farias et al. (1992), Barros et al. (1996), Pietrobom \& Barros (2000, 2001, 2002, 2003) e Santiago \& Barros (2003).

Na Zona da Mata norte de Pernambuco, sub-zona de mata úmida (Andrade-Lima 1961),

\footnotetext{
Artigo recebido em 02/2004. Aceito para publicação em 09/2006.

${ }^{1}$ Parte da Tese de Doutorado do primeiro autor. Apoio: CNPq e Fundação O Boticário de Proteção à Natureza. ${ }^{2}$ Museu Paraense Emílio Goeldi-MCT, Campus de Pesquisa, Coordenação de Botânica. Av. Perimetral, 1901, Terra Firme, 66017-970, Belém, PA. pietrobomsilva@yahoo.com ${ }^{3}$ Departamento de Botânica, Centro de Ciências Biológicas, Universidade Federal de Pernambuco, Av. Prof. Moraes Rego 1235, 50670-901, Recife, PE, Brasil.
} 
encontra-se um dos maiores fragmentos de floresta atlântica, considerado de extrema importância biológica (MMA 2000). O estudo da biodiversidade nele presente é de grande importância, por se tratar de uma das áreas ainda preservadas e pouco alteradas de floresta atlântica no estado. Desta forma, o presente trabalho visa contribuir com informações do ponto de vista florístico, bem como sobre os padrões de distribuição geográfica das pteridófitas em uma área de floresta atlântica na Zona da Mata norte de Pernambuco.

\section{Área de Estudo}

O fragmento florestal Água Azul está localizado no município de Timbaúba, zona da mata norte do estado de Pernambuco, mais especificamente mata setentrional, em áreas tradicionalmente açucareiras do estado (Barros et al. 2002), nas coordenadas geográficas de $35^{\circ} 22^{\prime} 42,9^{\prime \prime} \mathrm{W}-07^{\circ} 36^{\prime} 31,5^{\prime \prime} \mathrm{S}$, com altitudes que variam de 304-451 m.

A área de estudo está inserida no complexo das Serras do Mascarenhas e do Jundiá, que apresenta altitudes de 200 a 640 m (Beltrão \& Macedo 1994). O relevo é considerado por Silva (1990) como movimentado, constituído de colinas e extensas chãs, associado aos níveis do cristalino que antecedem o Planalto da Borborema, variando de ondulado a montanhoso e apresentando vertentes convexas e vales em "V".

O clima é o As' (quente e úmido) segundo a classificação de Köeppen (Beltrão \& Macedo 1994), com temperatura variando entre $26-27,5^{\circ} \mathrm{C}$, e os meses de abril, junho, julho e agosto com maior precipitação de chuva (dados fornecidos pelo Instituto Nacional de Meteorologia - INMET, correspondendo ao período de 2000 a 2003, estação Recife - PE).

$\mathrm{O}$ fragmento abrange cerca de 600 ha e, considerando a classificação de Veloso et al. (1991), a vegetação da área se enquadra no tipo Floresta Ombrófila Densa Submontana e representa um dos poucos remanescentes de floresta úmida da região da Zona da Mata norte de Pernambuco (Andrade-Lima 1960).
O fragmento florestal é originalmente composto de árvores de troncos retos com esgalhamentos altos, copas em pára-sol e folhas pequena. $O$ porte de algumas espécies alcança em torno de $10 \mathrm{~m}$ e as espécies herbáceas são constituídas por epífitas e gramíneas além de musgos e liquens (Silva 1990).

\section{Material e Métodos}

O levantamento florístico foi realizado nos meses de novembro de 2000, janeiro, março, maio e dezembro de 2001. Os espécimes foram coletados e herborizados seguindo o método padrão para plantas vasculares de acordo com Mori et al. (1989) e Windisch (1992). Os táxons foram identificados a partir de bibliografia específica para cada família, bem como pelo envio de duplicatas para a confirmação e/ou identificação por especialistas.

O sistema de classificação adotado para a seqüência de apresentação dos táxons segue o de Kramer \& Green (1990), com modificações para o tratamento das famílias Cyatheaceae por Lellinger (1987), Thelypteridaceae por Smith (1992), Vittariaceae por Crane (1997) e para os gêneros Microgramma e Pleopeltis por Tryon \& Tryon (1982), Actinostachys por Riba \& Pacheco (1995) e Gleichenella por Østergaard-Andersen \& Øllgaard (2001).

Os nomes dos autores dos táxons foram padronizados de acordo com Pichi-Sermolli (1996).

O material testemunho foi depositado no herbário do Departamento de Botânica da Universidade Federal de Pernambuco (UFP), com duplicatas enviadas para diversos herbários nacionais e estrangeiros.

Os padrões de distribuição geográfica dos táxons foram estabelecidos de acordo com Lima et al. (1997):

Neotropicais: NEO - espécies que ocorrem em formações do Continente Americano, tendo o Sul da Flórida (Estados Unidos da América), a Argentina ou até o Chile como limites máximos ao Norte e ao Sul, respectivamente; AS - espécies exclusivas dos países da América do Sul; BR - espécies endêmicas do Brasil. 
Pantropicais: PAN - espécies que ocorrem com ampla distribuição nos trópicos do Velho e Novo Mundo, comuns às floras da Ásia, África, Malásia, América Central e do Sul.

A análise dos hábitos foi baseada em observações realizadas no campo.

A caracterização das espécies quanto às formas de vida baseou-se na chave proposta por Mueller-Dombois \& Ellemberg (1974), que está fundamentada no sistema proposto por Raunkiaer. Considerou-se as seguintes categorias: fanerófita rosulada; caméfita rosulada; hemicriptófita rosulada, reptante e rizomatosa; geófita rizomatosa, rosulada e reptante; helófita rosulada e liana. Quanto às epífitas e hemiepífitas, adotou-se as modificações propostas por Sota (1971) e Senna \& Waechter (1997): epífita pendente, reptante e rosulada; hemiepífita escandente.

Os ambientes preferenciais foram baseados em observações de campo realizadas pelo primeiro autor.

\section{Resultados e Discussão}

O inventário das pteridófitas do fragmento florestal Água Azul revelou uma riqueza florística de 16 famílias, 42 gêneros e 85 espécies (Tab. 1). Levando em consideração o tamanho da área de estudo, o inventário realizado é bastante significativo, pois constitui quase $1 / 3$ do total das espécies de pteridófitas já registradas para Pernambuco de acordo com Barros et al. (2002).

As famílias de maior riqueza específica foram Pteridaceae (18 spp.), seguidas de Polypodiaceae (10 spp.) e Dryopteridaceae (10 spp.) e Thelypteridaceae (8 spp.); em número de gêneros destacam-se Dryopteridaceae, Polypodiaceae com sete gêneros cada e Pteridaceae com seis. Os gêneros com maior número de espécies foram Adiantum, com 12 e Thelypteris, com sete espécies (Tab. 1).

De maneira geral, a representatividade expressiva das famílias e dos gêneros acima relacionados pode ser vista em outros trabalhos de florística de pteridófitas como os realizados por Salino (1996), Santos \& Barros (1999),
Pietrobom \& Barros (2002) e Melo \& Salino (2002), onde estes táxons sempre se destacam dentre os componentes da pteridoflora brasileira.

No estado de São Paulo, na Serra do Cuscuzeiro (Salino 1996) e em três remanescentes de mata de galeria da bacia do Rio JacaréPepira (Salino \& Joly 2001) citam o gênero Thelypteris com maior número de espécies (15 e 14, respectivamente). O número de espécies de Thelypteris presentes nestas áreas pode estar relacionado à diversidade de formações vegetacionais (florestas semidecíduas, cerrado "senso lato", florestas de galeria, brejos permanentes e cerrado com afloramentos de arenito), já que algumas espécies preferem locais expostos ao sol e outras, locais sombreados no interior das matas (Salino 1996). $\mathrm{Na}$ área estudada, também foi registrado número elevado de espécies de Thelypteris, observadas principalmente em locais abertos e encharcados ou ao longo dos cursos de água.

Xavier (2003) ao estudar as pteridófitas em um remanescente de floresta serrana no estado de Pernambuco comenta que o gênero Adiantum é mais representativo em áreas de mata secundária, sendo pobre em áreas de mata primária. Situações semelhantes foram registradas na área estudada e em outras como, por exemplo, Pietrobom \& Barros (2002) e Graçano et al. (1998) que também observaram um número elevado de espécies para esses dois gêneros.

A análise do padrão de distribuição geográfica contou com 83 espécies e apontou a predominância de elementos neotropicais. A maioria das espécies de pteridófitas inventariadas na área estudada (54 spp.) enquadra-se nesse padrão, como por exemplo Polypodium Dulce, Thelypteris abrupta e Trichomanes scandens (Tab. 1).

$\mathrm{Na}$ área estudada ocorrem nove táxons com ampla distribuição em regiões tropicais do Velho e Novo Mundo (Tab. 1), como exemplo, podem ser citadas Macrothelypteris torresiana, Nephrolepis biserrata, Pityrogramma calomelanos var. calomelanos e Vittaria lineata. 
Dentre os táxons registrados na área estudada, 12 ocorrem apenas na América do Sul (Tab. 1), como Danaea bipinnata, Lindsaea pallida, Polytaenium guayanense e Triplophyllum dicksonioides.

Oito táxons são endêmicos ao Brasil (BR): Adiantum diogoanum, Ctenitis distans, Cyathea abreviata, C. praecincta, Cyclodium heterodon var. abbreviatum, Microgramma geminata, Polybotrya cylindrica e Thelypteris polypodioides. Destas Adiantum diogoanum, Cyathea abreviata, Cyclodium heterodon var. abbreviatum e Microgramma geminata destacam-se por apresentarem distribuição geográfica mais restrita no Brasil.

Verifica-se que a maioria dos táxons são hemicriptófitos rosulados que crescem no solo (terrícolas), ocorrendo predominantemente em barrancos junto à cursos d'água no interior da mata. De um modo geral, estes resultados são semelhantes ao encontrados por Barros et al. (2002) para o estado.

Entre as espécies de pteridófitas, as hemicriptófitas são as que têm ampla distribuição e que ocorrem em uma maior diversidade de hábitats (Pereira-Noronha 1989). Entre essas formas de hemicriptófitas encontradas, o tipo rosulado parece ser favorecido na disputa pelo espaço no substrato e por melhores condições para a captação de luz no interior das florestas (Senna \& Waechter 1997). Estes dados são concordantes com os encontrados na área de estudo justificando, assim, a predominância desta forma de vida.

Foram observadas nove epífitas (Anathacorus angustifolius, Dicranoglossum desvauxii, D. furcatum, Microgramma geminata, $M$. lycopodioides, $M$. vacciniifolia, Pleopeltis astrolepis, Trichomanes scandens e Vittaria lineata); e oito rupícolas (Asplenium cristatum, A. formosum, Hemionitis palmata, Polypodium dulce, Polytaenium guayanense, Selaginella sp., Trichomanes hymenoides e T. krausii).

Constatou que as espécies encontradas sobre afloramentos rochosos não ocorrem sobre a rocha nua, apresentando-se sempre associadas a uma camada de húmus.
As epífitas aparecem como a segunda forma biológica mais representativa, sendo as reptantes as mais numerosas (5 spp.), as rosuladas com três espécies e as pendentes com uma. As outras formas biológicas registradas, com menor expressividade de espécies, foram as geófitas com quatro rizomatosas, uma rosulada e uma reptante; as hemiepífitas escandentes e fanerófitas rosuladas, com três espécies cada; as lianas com três espécies e as caméfitas rosuladas, com duas espécies.

O predomínio das espécies terrícolas está relacionado à maior oferta de nutrientes e diversidade de condições, pois como comentou Sota (1971), o ambiente epifítico caracterizase pela pouca oferta de nutrientes se comparado com o ambiente terrestre. Segundo Tuomisto \& Ruokolainen (1994), este fato influencia a distribuição das espécies através das variadas condições físico-químicas do solo, como a irradiação solar, a temperatura e a umidade ambiental.

Com base nas observações de campo mais da metade das espécies (60 spp.) demonstrou apresentar uma exclusividade para algum tipo de ambiente em particular (Tab. 1). Desta forma, foram determinados sete padrões:

1. Espécies encontradas em barrancos de cursos de água no interior da mata (A1), com 19 registros. 2. Espécies encontradas em afloramentos rochosos no interior da mata (A2), com 13 registros. 3. Espécies encontradas em encostas no interior da mata (A3), com sete registros. 4. Espécies encontradas em borda de trilhas no interior da mata (A4), com 12 registros. 5. Espécies encontradas na borda da mata (A5), com sete registros. 6. Espécies encontradas em locais paludosos no interior da mata (A6), com dois registros. 7. Espécies que não demonstraram preferência em um tipo de ambiente (A7), com 25 registros.

Acredita-se que as espécies enquadradas no tipo 7 possuem uma grande amplitude ecológica (plasticidade), o que permite que se estabeleçam em mais de um tipo de ambiente preferencial, ao contrário daquelas com requisitos restritos e que só se estabeleceram em ambientes específicos (Mynssen 2000). 
De forma semelhante, trabalhos realizados com as pteridófitas em Pernambuco apresentam dados similares aos aqui apresentados, onde as pteridófitas ocupam preferencialmente ambientes ocorrentes no interior dos fragmentos florestais (Ambrósio \& Barros 1997; Santos \& Barros 1999; Barros et al. 2001, 2002; Farias et al. 1992; FonsecaDias et al. 2001; Pietrobom \& Barros 2000, 2001, 2002; Santiago \& Barros 2003).

Tabela 1 - Pteridófitas do fragmento florestal Água Azul, município de Timbaúba, Pernambuco, Brasil. Ambientes preferenciais: (A1) - Espécies encontradas em barranco de cursos d'água no interior da mata; (A2) - Espécies encontradas em afloramentos rochosos no interior da mata; (A3) - Espécies encontradas em encosta no interior da mata; (A4) - Espécies encontradas em borda de trilhas no interior da mata; (A5) - Espécies encontradas na borda da mata; (A6) - Espécies encontradas em locais paludosos no interior da mata; (A7) - Espécies que não demonstraram preferência em um tipo de ambiente.

\begin{tabular}{|c|c|c|c|c|}
\hline $\begin{array}{l}\text { FAMÍLIAS } \\
\text { Espécies }\end{array}$ & $\begin{array}{l}\text { Padrão de } \\
\text { Distribuição } \\
\text { Geográfica }\end{array}$ & $\begin{array}{l}\text { Ambientes } \\
\text { preferenciais }\end{array}$ & Formas de vida & $\begin{array}{l}\text { Material } \\
\text { testemunho(UFP) }\end{array}$ \\
\hline \multicolumn{5}{|l|}{ ASPLENIACEAE } \\
\hline Asplenium cristatum Lam. & Neotropical & A 3 & Hemicriptófita rosulada & Pietrobom et al. 5199 \\
\hline A. formosum Willd. & Pantropical & A3 & Hemicriptófita rosulada & Pietrobom et al. 5409 \\
\hline A. serratum $\mathrm{L}$. & Neotropical & A3 & Hemicriptófita rosulada & Pietrobom et al. 5429 \\
\hline \multicolumn{5}{|l|}{ BLECHNACEAE } \\
\hline Blechnum brasiliense Desv. & Neotropical & A7 & Caméfita rosulada & Pietrobom et al. 5406 \\
\hline B. occidentale $\mathrm{L}$. & Neotropical & A7 & Hemicriptófita rosulada & Pietrobom et al. 5060 \\
\hline B. serrulatum Rich. & Neotropical & A5 & Geófita rizomatosa & $\begin{array}{l}\text { Santos et al. } 134 \\
\text { (PEUFR) }\end{array}$ \\
\hline $\begin{array}{l}\text { Salpichlaena volubilis (Kaulf.) } \\
\text { Hook. }\end{array}$ & Neotropical & A 1 & Liana & $\begin{array}{l}\text { Pietrobom et al. } \\
5425\end{array}$ \\
\hline \multicolumn{5}{|l|}{ CYATHEACEAE } \\
\hline Cyathea abreviata Fernandes & Brasil & A7 & Caméfita rosulata & Pietrobom et al. 5415 \\
\hline C. microdonta (Desv.) Domin & Neotropical & A 1 & Fanerófita rosulada & Pietrobom et al. 5262 \\
\hline C. phalerata Mart. & América do Sul & A 1 & Fanerófita rosulada & Pietrobom et al. 5070 \\
\hline C. praecincta (Kunze) Domin & Brasil & A1 & Fanerófita rosulada & Pietrobom et al. 5078 \\
\hline \multicolumn{5}{|l|}{ DENNSTAEDTIACEAE } \\
\hline $\begin{array}{l}\text { Lindsaea lancea (L.) Bedd. } \\
\quad \text { var. lancea }\end{array}$ & Pantropical & A7 & Hemicriptófita reptante & Pietrobom et al. 5417 \\
\hline L. pallida Klotzsch & América do Sul & A4 & Hemicriptófita reptante & Pietrobom et al. 4647 \\
\hline \multicolumn{5}{|l|}{ DRYOPTERIDACEAE } \\
\hline Ctenitis distans (Brack.) Ching & Brasil & A7 & Hemicriptófita rosulada & Pietrobom et al. 5435 \\
\hline \multicolumn{5}{|l|}{ DRYOPTERIDACEAE } \\
\hline $\begin{array}{l}\text { Cyclodium heterodon (Schrad.) } \\
\text { Moore var. abbreviatum } \\
\text { (C. Presl) A.R. Sm. }\end{array}$ & Brasil & A7 & Hemicriptófita rosulada & Pietrobom et al. 5209 \\
\hline $\begin{array}{l}\text { C. meniscioides (Willd.) } \\
\text { C. Preslvar. meniscioides }\end{array}$ & Neotropical & A7 & Hemicriptófita reptante & Pietrobom et al. 5431 \\
\hline $\begin{array}{l}\text { Diplazium cristatum (Desv.) } \\
\text { Aslton }\end{array}$ & Neotropical & A1 & Hemicriptófita rosulada & Pietrobom et al. 5421 \\
\hline
\end{tabular}




\begin{tabular}{|c|c|c|c|c|}
\hline $\begin{array}{l}\text { FAMÍLIAS } \\
\text { Espécies }\end{array}$ & $\begin{array}{l}\text { Padrão de } \\
\text { Distribuição } \\
\text { Geográfica }\end{array}$ & $\begin{array}{l}\text { Ambientes } \\
\text { preferenciais }\end{array}$ & Formas de vida & $\begin{array}{c}\text { Material } \\
\text { testemunho(UFP) }\end{array}$ \\
\hline Megalastrum sp. & & A1 & Hemicriptófita rosulada & Pietrobom et al. 5225 \\
\hline Polybotrya cylindrica Kaulf. & Brasil & A1 & Hemiepífita escandente & Pietrobom et al. 5081 \\
\hline Tectaria incisa Cav. & Neotropical & A1 & Hemicriptófita rosulada & Pietrobom et al. 5228 \\
\hline $\begin{array}{l}\text { Triplophyllum dicksonioides } \\
\text { (Fée) Holttum }\end{array}$ & América do Sul & A7 & Hemicriptófita rizomatosa & Pietrobom et al. 5414 \\
\hline $\begin{array}{l}\text { T. funestum (Kunze) Holttum } \\
\text { var. funestum }\end{array}$ & Neotropical & A3 & Hemicriptófita rizomatosa & $\begin{array}{l}\text { Barros et al. s.n. } \\
\text { (PEUFR-16639) }\end{array}$ \\
\hline $\begin{array}{l}\text { T. funestum (Kunze) Holttum } \\
\text { var. perpilosum Holttum }\end{array}$ & América do Sul & A4 & Hemicriptófita rizomatosa & Pietrobom et al. 5454 \\
\hline \multicolumn{5}{|l|}{ GLEICHENIACEAE } \\
\hline $\begin{array}{l}\text { Dicranopteris flexuosa (Schrad.) } \\
\text { Underw. }\end{array}$ & Neotropical & A5 & Geófita rizomatosa & Pietrobom et al. 5253 \\
\hline Gleichenella pectinata (Willd.) Ching & Neotropical & A5 & Geófita rizomatosa & Pietrobom et al. 4636 \\
\hline \multicolumn{5}{|l|}{ HYMENOPHYLLACEAE } \\
\hline Trichomanes hymenoides Hedw. & Neotropical & A2 & Hemicriptófita reptante & Pietrobom et al. 5218 \\
\hline T. krausii Hook. \& Grev. & Neotropical & A2 & Hemicriptófita reptante & Pietrobom et al. 5437 \\
\hline T. pinnatum Hedw. & Neotropical & A4 & Hemicriptófita rosulada & Pietrobom et al. 5453 \\
\hline T. scandens $\mathrm{L}$. & Neotropical & $\mathrm{A} 3$ & Epífita reptante & $\begin{array}{l}\text { Barros et al. } \\
\text { (PEUFR-16641) }\end{array}$ \\
\hline \multicolumn{5}{|l|}{ LOMARIOPSIDACEAE } \\
\hline $\begin{array}{l}\text { Lomagramma guianensis } \\
\text { (Aubl.) Ching }\end{array}$ & Neotropical & A7 & Hemiepífita escandente & Pietrobom et al. 5411 \\
\hline Lomariopsis japurensis (Mart.) Sm. & Neotropical & A2 & Hemiepífita escandente & Pietrobom et al. 5090 \\
\hline \multicolumn{5}{|l|}{ MARATTIACEAE } \\
\hline Danaea bipinnata $\mathrm{H}$. Tuomisto & América do Sul & A1 & Hemicriptófita rosulada & Pietrobom et al. 5413 \\
\hline D. elliptica $\mathrm{Sm}$. & Neotropical & A7 & Hemicriptófita rosulada & Pietrobom et al. 5459 \\
\hline D. nodosa (L.) Sm. & Neotropical & $\mathrm{A} 1$ & Geófita rosulada & Pietrobom et al. 5258 \\
\hline \multicolumn{5}{|l|}{ NEPHROLEPIDACEAE } \\
\hline Nephrolepis biserrata (Sw.) Schott & t Pantropical & A6 & Hemicriptófita rosulada & Pietrobom et al. 5088 \\
\hline N. rivularis (Vahl) Krug & Neotropical & A1 & Hemicriptófita rosulada & Pietrobom et al. 4782 \\
\hline \multicolumn{5}{|l|}{ POLYPODIACEAE } \\
\hline $\begin{array}{l}\text { Campyloneurum repens (Aubl.) } \\
\text { C. Presl }\end{array}$ & Neotropical & A1 & Hemicriptófita reptante & Pietrobom et al. 5418 \\
\hline $\begin{array}{l}\text { Dicranoglossum desvauxii } \\
\text { (Klotzsch) Proctor }\end{array}$ & Neotropical & A4 & Epífita rosulada & Pietrobom et al. 5071 \\
\hline D. furcatum (L.) J. Sm. & Neotropical & A4 & Epífita rosulada & Pietrobom et al. 4780 \\
\hline $\begin{array}{l}\text { Microgramma geminata (Schrad.) } \\
\text { R.M Tryon \& A.F. Tryon }\end{array}$ & Brasil & A4 & Epífita pendente & Pietrobom et al. 4768 \\
\hline M. lycopodioides (L.) Copel. & Pantropical & A4 & Epífita reptante & Pietrobom et al. 5456 \\
\hline $\begin{array}{l}\text { M. vacciniifolia (Langsd. } \\
\text { \& Fisch.) Copel. }\end{array}$ & Neotropical & A4 & Epífita reptante & Pietrobom et al. 4769 \\
\hline $\begin{array}{l}\text { Niphidium crassifolium } \\
\text { (L.) Lellinger }\end{array}$ & Neotropical & A4 & Hemicriptófita rosulada & Barros etal.s.n.PEUFR \\
\hline
\end{tabular}




\begin{tabular}{|c|c|c|c|c|}
\hline $\begin{array}{l}\text { FAMÍLIAS } \\
\text { Espécies }\end{array}$ & $\begin{array}{l}\text { Padrão de } \\
\text { Distribuição } \\
\text { Geográfica }\end{array}$ & $\begin{array}{l}\text { Ambientes } \\
\text { preferenciais }\end{array}$ & Formas de vida & $\begin{array}{c}\text { Material } \\
\text { testemunho(UFP) }\end{array}$ \\
\hline $\begin{array}{l}\text { Pecluma ptilodon (Kunze) M.G. } \\
\text { Pricevar. ptilodon }\end{array}$ & América do Sul & A2 & Hemicriptófita rosulada & Pietrobom et al. 5207 \\
\hline $\begin{array}{l}\text { Pleopeltis astrolepis (Liebm.) } \\
\text { E. Fourn. }\end{array}$ & Neotropical & A4 & Epífita reptante & Pietrobom et al. 5203 \\
\hline Polypodium dulce Poir. & Neotropical & A7 & Hemicriptófita reptante & Pietrobom et al. 5201 \\
\hline \multicolumn{5}{|l|}{ PTERIDACEAE } \\
\hline Adiantopsis radiata (L.) Fee & Neotropical & A7 & Hemicriptófita rosulada & Pietrobom et al. 5442 \\
\hline Adiantum argutum Splitg. & América do Sul & A7 & Hemicriptófita reptante & Pietrobom et al. 5087 \\
\hline A. deflectens Mart. & Neotropical & A4 & Hemicriptófita rosulada & Pietrobom et al. 4639 \\
\hline A. diogoanum Glaz. ex Baker & Brasil & A7 & Hemicriptófita reptante & Pietrobom et al. 5285 \\
\hline A. dolosum Kunze & Neotropical & A7 & Hemicriptófita reptante & Pietrobom et al. 5286 \\
\hline A. glaucescens Klotzsch & América do Sul & A4 & Hemicriptófita reptante & Pietrobom et al. 4658 \\
\hline A. humile Kunze & Neotropical & A7 & Hemicriptófita reptante & Pietrobom et al. 5403 \\
\hline A. latifolium Lam. & Neotropical & A7 & Hemicriptófita reptante & Pietrobom et al. 5276 \\
\hline A. obliquum Willd. & Neotropical & A7 & Hemicriptófita reptante & Félix et al. 8487 PEUFR \\
\hline A. petiolatum Desv. & Neotropical & A7 & Hemicriptófita reptante & Pietrobom et al. $5423 \mathrm{a}$ \\
\hline A. pulverulentum $\mathrm{L}$. & Neotropical & A7 & Hemicriptófita reptante & Pietrobom et al. 5277 \\
\hline $\begin{array}{l}\text { A. serratodentatum Humb. \& } \\
\text { Bonpl. ex Willd. }\end{array}$ & Neotropical & A5 & Geófita rizomatosa & Pietrobom et al. 5255 \\
\hline A. terminatum Kunze ex Miq. & Neotropical & A4 & Hemicriptófita reptante & Pietrobom et al. 4655 \\
\hline $\begin{array}{l}\text { Doryopteris pedata }(\mathrm{L} .) \text { Fée var. } \\
\text { multipartita (Fee) R.M. Tryon }\end{array}$ & América do Sul & A2 & Hemicriptófita rosulada & Pietrobom et al. 5445 \\
\hline Hemionitis palmata $\mathrm{L}$. & Neotropical & $\mathrm{A} 2$ & Hemicriptófita rosulada & Pietrobom et al. 5408 \\
\hline $\begin{array}{l}\text { Pityrogramma calomelanos (L.) } \\
\text { Link var. calomelanos }\end{array}$ & Pantropical & A7 & Hemicriptófita rosulada & Pietrobom et al. 4633 \\
\hline Pteris biaurita $\mathrm{L}$. & Pantropical & A1 & Hemicriptófita rosulada & $\begin{array}{l}\text { Bocage } \text { et al. } \\
\quad \text { (PEUFR-11528) }\end{array}$ \\
\hline P. denticulata Sw. var. denticulata & Neotropical & A1 & Hemicriptófita rosulada & Pietrobom et al. 5214 \\
\hline \multicolumn{5}{|l|}{ SCHIZAEACEAE } \\
\hline Actinostachys pennula (Sw.) Hook. & Neotropical & $\mathrm{A} 3$ & Hemicriptófita rosulada & Andrade-Lima 5535 \\
\hline Anemia hirta (L.) Sw. & Neotropical & A7 & Hemicriptófita rosulada & Pietrobom et al. 5269 \\
\hline A. phyllitidis (L.) Sw. & Neotropical & A1 & Hemicriptófita rosulada & Pietrobom et al. 5213 \\
\hline $\begin{array}{l}\text { A. villosa Humb. \& Bonpl. } \\
\text { ex Willd. }\end{array}$ & América do Sul & A3 & Hemicriptófita rosulada & $\begin{array}{l}\text { Barros et al. } \\
\text { (UFP-11086) }\end{array}$ \\
\hline Lygodium venustum $\mathrm{Sw}$. & Neotropical & A5 & Liana & $\begin{array}{l}\text { Bocage et al. } \\
\text { (IPA-52456) }\end{array}$ \\
\hline L. volubile Sw. & Neotropical & A5 & Liana & Pietrobom et al. 4642 \\
\hline Schizaea elegans (Vahl) Sm. & Neotropical & A4 & Hemicriptófita rosulada & Pietrobom et al. 4767 \\
\hline \multicolumn{5}{|l|}{ SELAGINELLACEAE } \\
\hline Selaginella muscosa Spring & América do Sul & $\mathrm{A} 2$ & Hemicriptófita reptante & Pietrobom et al. 5449 \\
\hline Selaginella sp. & & $\mathrm{A} 2$ & Hemicriptófita reptante & Pietrobom et al. 4646 \\
\hline \multicolumn{5}{|l|}{ THELYPTERIDACEAE } \\
\hline $\begin{array}{l}\text { Macrothelypteris torresiana } \\
\text { (Gaudich) Ching }\end{array}$ & Pantropical & A1 & Hemicriptófita rosulada & Pietrobom et al. 4635 \\
\hline
\end{tabular}




\begin{tabular}{|c|c|c|c|c|}
\hline $\begin{array}{l}\text { FAMÍLIAS } \\
\text { Espécies }\end{array}$ & $\begin{array}{l}\text { Padrão de } \\
\text { Distribuição } \\
\text { Geográfica }\end{array}$ & $\begin{array}{l}\text { Ambientes } \\
\text { preferenciais }\end{array}$ & Formas de vida & $\begin{array}{c}\text { Material } \\
\text { testemunho(UFP) }\end{array}$ \\
\hline $\begin{array}{l}\text { Thelypteris abrupta } \\
\text { (Desv.) Proctor }\end{array}$ & Neotropical & A1 & Hemicriptófita rosulada & Pietrobom et al. 5275 \\
\hline T. biolleyi (Christ) Proctor & Neotropical & A1 & Hemicriptófita rosulada & Pietrobom et al. 5283 \\
\hline T. hispidula (Decne.) C.F. Reed & Pantropical & A7 & Hemicriptófita rosulada & Pietrobom et al. 5265 \\
\hline $\begin{array}{l}\text { T. macrophylla (Kunze) } \\
\text { C.V. Morton }\end{array}$ & Neotropical & A6 & Geófita reptante & Pietrobom et al. 5433 \\
\hline T. poiteana (Bory) Proctor & Neotropical & A1 & Hemicriptófita rosulada & $\begin{array}{l}\text { Lima et al. } \\
\quad \text { (PEUFR-11357) }\end{array}$ \\
\hline T. polypodioides (Raddi) C.F. Reed & Brasil & A7 & Hemicriptófita reptante & Pietrobom et al. 5032 \\
\hline T. serrata (Cav.) Alston & Neotropical & A7 & Hemicriptófita reptante & Pietrobom et al. 5063 \\
\hline \multicolumn{5}{|l|}{ VITTARIACEAE } \\
\hline $\begin{array}{l}\text { Ananthacorus angustifolius } \\
\text { Underw. \& Maxon }\end{array}$ & Neotropical & A3 & Epífita reptante & Pietrobom et al. 5086 \\
\hline Anetium citrifolium (L.) Splitg. & Neotropical & A2 & Hemicriptófita reptante & $\begin{array}{l}\text { Barros et al. } \\
\text { (PEUFR-32886) }\end{array}$ \\
\hline $\begin{array}{l}\text { Polytaenium guayasense } \\
\text { (Hieron.) Alston }\end{array}$ & América do Sul & $\mathrm{A} 2$ & Hemicriptófita reptante & Pietrobom et al. 4373 \\
\hline Vittaria lineata (L.) Sm. & Pantropical & A3 & Epífita rosulada & Félix et al. 8490 \\
\hline
\end{tabular}

\section{Agradecimentos}

Os autores agradecem à colaboração da Dra. Lana da Silva Sylvestre, da Universidade Federal Rural do Rio de Janeiro, do Dr. Alexandre Salino, da Universidade Federal de Minas Gerais e do Dr. Jefferson Prado, do Instituto de Botânica de São Paulo, pela confirmação e/ou identificação de espécies dos gêneros Asplenium, Thelypteris, Ctenitis e Adiantum, respectivamente. Agradecem também o apoio da Diretoria da Usina Cruangi, pelo auxílio com hospedagem e mateiro; ao Conselho Nacional de Desenvolvimento Científico e Tecnológico $(\mathrm{CNPq})$ pela bolsa de estudos do primeiro autor e à Fundação $\mathrm{O}$ Boticário de Proteção à Natureza, pelo suporte financeiro.

\section{REFERÊNCIAS BIBLIOGRÁFICAS}

Ambrósio, S. T. \& Barros, I. C. L. 1997. Pteridófitas de uma área remanescente de floresta atlântica do estado de Pernambuco, Brasil. Acta Botanica Brasilica 11(2): 105-113.

Andrade-Lima, D. 1960. Estudos fitogeográficos de Pernambuco. Arquivos do Instituto Pesquisas Agronômicas 5: 305-341.
1961. Tipos de floresta de Pernambuco. Anais da Associação dos Geógrafos Brasileiros 12: 69-85.

Barros, I. C. L.; Fonseca. E. R.; Valdevino, J. A. \& Paula, E. L. 1996. Contribuição ao estudo taxonômico das pteridófitas ocorrentes na Reserva Ecológica de Caetés-Paulista, PE. Boletim da Sociedade Broteriana 67 (série 2): 271-286.

Barros, I. C. L.; Pietrobom, M. R.; Baracho, G. S.; Siqueira, J. A.; Santos, V. G. \& Moura, A. M. 2001. Contribution to the study of pteridophytes of the Serra do Urubú, Maraial municipality Pernambuco state, Northeastern Brazil (Marattiaceae Vittariaceae). Anales del Jardín Botánico Madrid 58(2): 303-310.

Barros, I. C. L.; Santiago, A. C. P.; Xavier, S. R. S.; Pietrobom, M. R. \& Luna, C. P. L. 2002. Diversidade e aspectos ecológicos das pteridófitas (avencas, samambaias e plantas afins) ocorrentes em Pernambuco. In: Tabarelli, M. \& Silva, J. M. C. (orgs.). Diagnóstico da Biodiversidade de Pernambuco. Vol.1. Editora Massangana e SECTMA, Recife. Pp. 153-171. 
Beltrão, A. L. \& Macêdo, M. M. L. 1994. Projeto Piloto da bacia Hidrográfica do Rio Goiana (macrozoneamento). Subsídios ao planejamento integrado da bacia do Rio Goiana: complexo serras do Mascarenhas e Jundiá. CPRH, Recife, 45p.

Crane, E. H. A 1997. Revised circumscription of the genera of the fern family Vittariaceae. Systematic Botany 22(3): 509-517.

Farias, M. C. A.; Belo, M. A. M. \& Barros, I. C. L. 1992. Pteridófitas da Reserva de Caetés (Paulista-PE). Boletim da Sociedade Broteriana 65(série 2): 147-162.

Fonseca-Dias, E. R.; Pôrto, K. C.; Barros, I. C. L. \& Mariz, G. 2001. New recordings of Pteridophytes for the state of Pernambuco, Northeast Brazil. Boletín Ecotrópica: Ecosistemas Tropicales 34: 31-41.

Graçano, D.; Prado, J. \& Azevedo, A. A. 1998. Levantamento preliminar de Pteridophyta do Parque Estadual do Rio Doce (MG). Acta Botanica Brasilica 12(2): 165-181.

Kramer, K. U. \& Green, P. S. 1990. Pteridophytes and Gymnosperms. In: Kubitzki, K. (ed.). The families and genera of vascular plants. Vol. I. Springer-Verlag, Berlin, 404p.

Lellinger, D. B. 1987. The disposition of Trichopteris (Cyatheaceae). American Fern Journal 77: 90-94.

Lima, M. P. M.; Guedes-Bruni, R. R.; Sylvestre, L. S.; Pessoa, S. V. A. \& Andreata, R. H. P. 1997. Padrões de distribuição geográfica das espécies vasculares da Reserva Ecológica de Macaé de Cima. In: Lima, H. C. \& Guedes-Bruni, R. R. (orgs.). Serra de Macaé de Cima: diversidade florística e conservação da Mata Atlântica. Instituto de Pesquisas Jardim Botânico do Rio de Janeiro, Rio de Janeiro. Pp.103-123.

Melo, L. C. N. \& Salino A. 2002. Pteridófitas de duas áreas de floresta da bacia do rio Doce no estado de Minas Gerais, Brasil. Lundiana 3(2): 129-139.
MMA - Ministério do Meio Ambiente. 2002. Avaliação e ações prioritárias para a conservação da biodiversidade da Mata Atlântica e Campos Sulinos. Conservation International do Brasil, Fundação SOS Mata Atlântica, Fundação Biodiversitas, Intituto de Pesquisas Ecológicas, Secretaria do Meio Ambiente do Estado de São Paulo, SEMAD/Instituto Estadual de Florestas MG. MMA/SBF, Brasília, 40p.

Mori, S. A.; Silva, L. A. M.; Lisboa, G. \& Coradin, L. 1989. Manual de manejo do herbário fanerogâmico. Centro de Pesquisa do Cacau, Ilhéus, 104p.

Mueller-Dombois, D. \& Ellemberg, H. 1974. Aims and methods of vegetation ecology. John Wiley, New York, 547p.

Mynssen, C. M. 2000. Pteridófitas da Reserva Rio das Pedras, Mangaratiba, RJ. Dissertação de Mestrado. Universidade Federal do Rio de Janeiro, Rio de Janeiro, 171p.

$\varnothing$ stergaard-Andersen, E. \& ØLlgaard, B. 2001. Gleicheniaceae. In: Harling, G. \& Andersson, L. (eds.). Flora of Ecuador. Botanical Institute, Göteborg University 66: 105-170.

Pereira-Noronha, M. R. 1989. Formas de vida e reprodução em Pteridófitas. Tese de Doutorado. Universidade Estadual Paulista, Rio Claro, 272p.

Pichi-Sermolli, R. E. G. 1996. Authors of scientific names in Pteridophyta. Royal Botanical Garden, Kew, 78p.

Pietrobom, M. R. \& Barros, I. C. L. 2000. Pteridoflora de la mata do estado, municipalidad de São Vicente Férrer, Pernambuco, Brasil: Davalliaceae, Blechnaceae, Lycopodiaceae y Selaginellaceae. Boletim da Sociedade Broteriana 70(série 2): 49-69.

.2001. Aspleniaceae (Pteridófita) da mata do estado, município de São Vicente Férrer, Pernambuco, Brasil. Leandra 16: 41-51.

2002. Pteridófitas de um remanescente de floresta atlântica em São Vicente Férrer, Pernambuco, Brasil: Pteridaceae. Acta Botanica Brasilica 16(4): 457-479. 
2003. Danaea bipinnata H.

Tuomisto (Marattiaceae - Pteridophyta), uma nova referência para o Brasil. Bradea 9(11): 51-54.

Riba, R. \& Pacheco, L. 1995. Actinostachys Wall. ex Hook. In: Moran, R. C. \& Riba, R. (eds.). Flora Mesoamericana 1. Psilotaceae a Salviniaceae. Universidad Nacional Autónoma de México, México. Pp. 52-53.

Salino, A. 1996. Levantamento das pteridófitas da Serra do Cuscuzeiro, Analândia, SP, Brasil. Revista Brasileira de Botanica 19(2): 173-178.

Salino, A. \& Joly, C. A. 2001. Pteridophytes of three remnants of gallery forests in the Jacaré-Pepira River Basin, São Paulo State, Brazil. Boletim Herbario Ezechias Paulo Heringer 8: 5-15.

Santiago, A. C. P \& Barros, I. C. L. 2003. Pteridoflora do Refúgio Ecológico Charles Darwin (Igarassu, Pernambuco, Brasil). Acta Botanica Brasilica 17(4): 596-604.

Santos, K. M. R. \& Barros, I. C. L. 1999. Pteridófitas das matas do Bituri Grande, Município de Brejo da Madre de Deus, estado de Pernambuco, Brasil. Memórias da Sociedade Broteriana 31(1): 1-109.

Senna, R. M. \& Waechter, J. L. 1997. Pteridófitas de uma floresta de Araucária. 1. Formas biológicas e padrões de distribuição geográfica. Iheringia (série bot.) 48: 41-58.

Silva, M. P. B. 1990. Caracterização ambiental do município de Timbaúba, Pernambuco.
Dissertação de Mestrado. Universidade Federal de Pernambuco, Recife, 87p.

Smith, A. R. 1992. Thelypteridaceae. In: Tryon, R. M. \& Stolze, R. G. (eds.). Pteridophyta of Peru. Fieldiana Botany 29: 1-80.

Sota, E. R. 1971. El epifitismo y las pteridofitas en Costa Rica (America Central). Nova Hedwigia 21: 401-465.

Tryon, R. M. \& Tryon, A. F. 1982. Ferns and allied plants with special reference to Tropical America. Springer-Verlag, New York, $867 \mathrm{p}$.

Tuomisto, H. \& Ruokolainen, K. 1994. Distribution of Pteridophyte and Melastomataceae along an edaphic gradient in an Amazonian rain forest. Journal Vegetation Science 5: 25-34.

Veloso, H. P.; Rangel Filho, A. L. R. \& Lima, J. C. A. 1991. Classificação da vegetação brasileira, adaptada a um sistema universal. IBGE, Rio de Janeiro, 124p.

Windisch, P. G. 1992. Pteridófitas da região norte-ocidental do estado de São Paulo Guia para excursões. 2 $2^{\underline{a}}$ ed. Editora Universitária-UNESP, São José do Rio Preto, 110p.

Xavier, S. R. 2003. Florística, aspectos ecológicos e conservação das Pteridófitas ocorrentes no Parque Ecológico João Vasconcelos Sobrinho (Caruaru Pernambuco - Brasil). Dissertação de Mestrado. Universidade Federal de Pernambuco, Recife, 62p. 